\title{
A Physics Teacher's Perspective on Action Oriented STSE Education
}

\section{Sarka Kubelikova, OCT}

Cawthra Park Secondary School
I have been teaching physics for 15 years. I have always looked for new approaches to engage students in the classroom, and to make them want to explore ideas outside of the class. My goal is to have students leave my classes with an admiration and wonder of the world around them, and to see the beauty of physics in everyday life.

Physics courses often fall short of making connections between science, society, technology and the environment (STSE), although this is the first expectation in every strand in the Science curriculum. I realized immediately that in today's changing job market, the intersectionality of these fields was crucial for our future generation to be successful.

I found that as I changed my teaching practices, my focus for my students also changed. I wanted to create a more holistic approach to physics. I didn't want class to just be a series of equations that students learned. I wanted to dive deeper into the concepts, applying big ideas on a more global scale.
As I grappled with how I was going to achieve this, I was introduced to research-informed and negotiated action (RiNA) projects. This idea seemed to align itself very well with what I was trying to achieve in the classroom. I agreed to be part of a research team, supported by a research team from OISE and a group of Peel District School Board Instructional Coaches. As a science teacher, I loved the idea of being part of a research team and modeling for my students how scientific inquiry can impact all walks of life.

I also knew that parts of this project would push me outside of my own comfort zone. I was familiar with teaching formulas and equations, but I was far less comfortable facilitating discussions and increasing the global consciousness of my students. Thankfully, working as part of a team, I felt supported enough to take on this challenge. During the first class, students were presented with some controversial statements regarding GPS devices becoming mandatory in all vehicles. Students chose to agree or disagree, and needed to defend their points of view. I noticed that as students had an open discussion, the class dynamic changed. Students felt that their opinions were heard, and were more likely to participate and speak up. 
At the beginning, some students struggled to accept this new way of teaching physics (although some classes were still taught in a "traditional" way, to reinforce the physics that they would need to understand their research). To get students fully on board, we explored the curriculum and discussed future goals. We looked at how this project could be applied in post-secondary fields and made connections to possible jobs.

As I led the students through a variety of activities, I realized that I was able to get to know the students quicker, as they had time to express themselves. Observing the students, and listening to their conversations about STSE topics, I was able to better understand their thinking patterns, and was able to document their growth in the application of physics in the real world.

At one point, as I observed the energy level in the class as students explained their research results to small groups of peers, I was impressed by how educated their explanations of their topics were. Their passion was evident in their involvement in class, and it didn't seem to matter whether students had strong mathematical skills or not. Everyone was involved and had their voices heard, including students with special education needs.
This experience was one of the most powerful of my career. Students were so passionate about their projects and topics that they wanted to showcase them to others. We organized and ran a fair at the school, where each student invited their guardians, their peers, and other guests. It was a huge success. Students used a variety of actions to solve STSE issues with a focus on physics. The energy was high, and students were proud of their accomplishments. I was fortunate enough to have another student record their presentations, so that we could review some of the highlights of the day. Video available here: https://bit.Iy/2G4j101

There were some significant outcomes from this teaching format. As part of their research, several students reached out to the scientific community. They contacted university professors and other professionals in the field. Some students were offered time in labs, and opportunities to work with teaching assistants at universities. This further engaged the students, as they could see the relevance of their research.

I am a strong believer that using RiNA projects in my classrooms helps students grow beyond the curriculum into active global citizens. I have incorporated this pedagogical framework into all of the courses that I teach. 